\begin{tabular}{l|l} 
Author(s): & $\begin{array}{l}\text { A. K. Zurek } \\
\text { W. R. Thissell } \\
\text { D. L. Tonks }\end{array}$
\end{tabular}

Submitted to:

Joint XV AIRAPT \& XXXIII EHPRG INTERNATIONAL CONFERENCE

Warsaw, Poland

September 11-15, 1995



Los Alamos Natlonal Laboratory, an affirmative actlon/equal opportunity employer, is operated by the University of California for the U.S. Department of Energy under contract W-7405-ENG-36. By acceptance of this article, the publisher recognizes that the U.S. Government retains a nonexcluslve, royaltyfree flcense to publish or reproduce the published form of thls contribution, or to allow others to do so, for U.S. Govemment purposes. The Los Alamos Natlonal Laboratory requests that the publlsher Identify this article as work performed under the auspices of the U.S. Department of Energy.

Thls is a preprint of a paper Intended for publication In a lournal or proceedings. Because changes may be made before publication, thls preprint is made avallable with the understanding that it will not be clted or reproduced without the permission of the author.

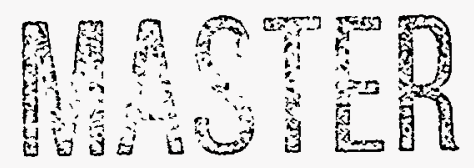




\section{DISCLAIMER}

Portions of this document may be illegible in electronic image products. Images are produced from the best available original document. 


\title{
SPALL BEHAVIOR AND DAMAGE EVOLUTION IN TANTALUM
}

\author{
A. K. Zurek, W. R. Thissell, and D. L. Tonks \\ Los Alamos National Laboratory \\ Los Alamos, NM 87545, U. S. A.
}

We conducted a number of plate impact experiments using an 80-mm launcher to study dynamic void initiation, linkup, and spall in tantalum. The tests ranged in shock pressure so that the transition from void initiation, incipient spall, and full spall could be studied. Wave profiles were measured using a velocity interferometry system (VISAR), and targets were recovered using "soft" recovery techniques. We utilized scanning electron microscopy, metallographic cross-sections, and plateau etching to obtain quantitative information concerning damage evolution in tantalum under spall conditions. The data (wave profiles and micrographs) are analyzed in terms of a new theory and model of dynamic damage cluster growth. We have developed a model of ductile damage based on void coalescence of initially nucleated voids, that leads to clusters of voids. At low loading strain rates, the biggest cluster has time to grow much more rapidly than smaller clusters to break the sample. At high loading strain rates, large clusters cannot grow any faster than smaller clusters so the sample breaks when enough clusters grow independently to form a fracture surface by random accumulation.

\section{Material and Experiment Description}

In this study we used commercially-pure (triple-electron-beam, arc melted) unalloyed -tantalum plate with the measured composition (in wt. \%) of carbon-6 ppm, nitrogen-24 ppm, oxygen-56 ppm, hydrogen- $<1 \mathrm{ppm}$, iron-19 ppm, nickel-25 ppm, chromium-9 ppm, tungsten-41 ppm, niobium-26 ppm and balance tantalum. The tantalum plate was in an annealed condition and had an equiaxed grain structure of 68 $\mu \mathrm{m}$ grain size [1]. We performed the uniaxial strain spall tests utilizing an $80-\mathrm{mm}$ single-stage launcher and recovery techniques as described previously [2]. Tantalum samples were spalled at 9.5 and 17 GPa pulse pressure and $1 \mu$ s pulse duration under symmetric impact conditions. Recovered spalled samples were analyzed using optical and scanning electron microscopes.

Previous, recovery and non-recovery spall tests reported 5.2 $\mathrm{GPa}$ spall strength for $6 \mathrm{GPa}$ shock amplitude, $7.3 \mathrm{GPa}$ spall strength for $9.5 \mathrm{GPa}$ shock amplitude, and 3.0 to $4.5 \mathrm{GPa}$ spall strength for $15 \mathrm{GPa}$ shock amplitude [1, 3, 4].

\section{Results and Discussion}

In this experiment we were particularly interested in the dynamic void initiation, void linkup and fracture by spall. Therefore, we have chosen the applied pulse pressure to either fully spall the sample or to introduce the spall surface but not to allow the surfaces to fully separate creating so called incipient spall. A typical VISAR spall trace is presented in Figure 1.

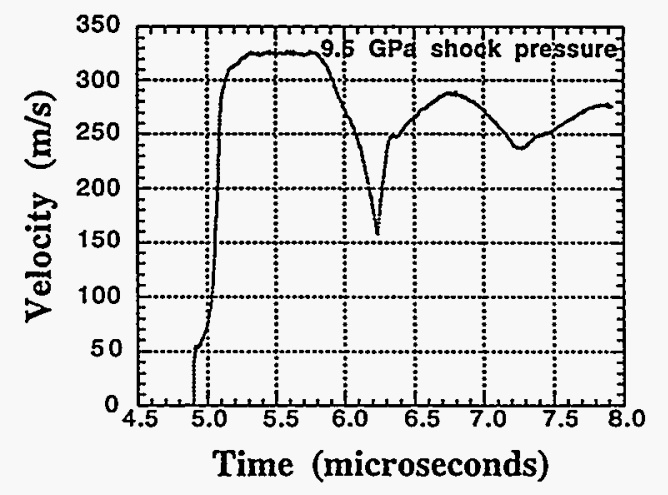

Figure 1. VISAR spall trace of tantalum spalled at $9.5 \mathrm{GPa}$. 
The spall test at $9.5 \mathrm{GPa}$ pulse pressure produced an incipient spall fracture. The cross section of the recovered spall sample showed a distinctive cracks running across the entire diameter of the sample with multiple branched and interlocking cracks extending into the sample away from the principal fracture surface. The two halves of the spall sample did not separated from each other, regardless of the fact that the pulse pressure exceeded the expected spall strength of this material. Figure 2 shows the optical micrograph of the cross section of the tantalum sample spalled at $9.5 \mathrm{GPa}$ shock pressure. We have sectioned off part of the spalled sample to allow it to separate the spall surfaces. Figure 3 shows the typical ductile dimple fracture surface characteristic for metals in Group $V_{A}$. Multiple impurities on the fracture surface are present, and most likely they are responsible for the voids initiation.



Figure 2. Cross section of tantalum sample spalled at $9.5 \mathrm{GPa}$ showing void initiation at point of intersection of several grains and propagating cracks with deformation surrounding a void and a crack.

Under increased loading pulse pressure $(17 \mathrm{GPa})$, the spall was complete and two halves of the spalled sample fully separated to reveal fracture surface. Scanning electron microscope pictures of the fractured surfaces showed a mixture of ductile dimple and cleavage fracture (Figure 4).

This change in the fracture morphology can be induced by the significant deformation twinning which will initiate cleavage [1]. The etched cross section, orthogonal to the spall fracture surface, reveals significant density of deformation twins and only few twins in the sample spalled at lower pulse pressure (compare Figure 2 with Figure 5).

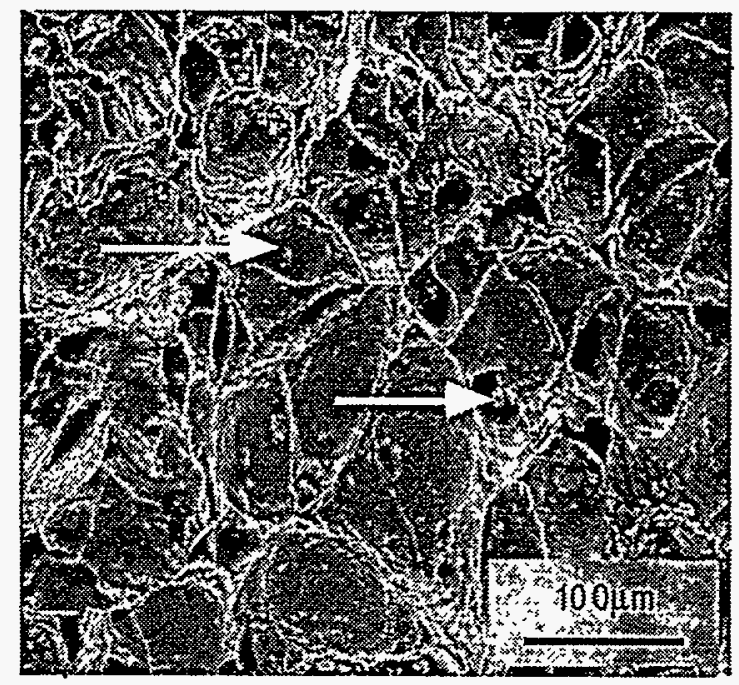

Figure 3. Spall fracture surface of tantalum spalled at 9.5 GPa. Arrows point to the particles which most likely initiated dimples on a ductile fracture surface.

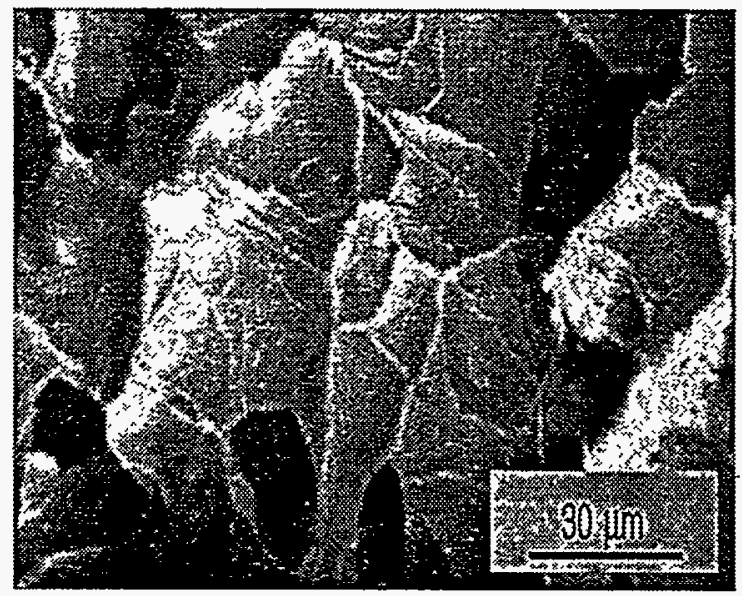

Figure 4. Fracture surface of tantalum spalled at 17 $\mathrm{GPa}$ shock pressure. The micrograph shows a mixture of cleavage fracture and ductile dimples present on the fracture surface.

In contrast, to the sample tested at the lower pulse amplitude, the crack branching is not so pronounced. This, and the change in mode fracture from ductile to mixture of ductile and cleavage fracture explains an observed decrease in spall strength with increased applied pulse amplitude in this material $[1,3,4]$.

Under severe loading rates or low temperatures the cleavage fracture is 
associated with the ductile-to-brittle transition in this material $[1,5]$.



Figure 5. Deformation twins present on the cross section of the tantalum sample spalled at $17 \mathrm{GPa}$ shock pressure.

With an increase in an applied stress, high hydrostatic tensile stress develop at the spall plane, and the stress at which the ductile-to-brittle transition occurs is pushed to the higher temperature since fracture stress is in the first approximation linearly proportional to the applied stress. The combination of this effect and significant amount of deformation twinning triggers cleavage fracture. It would be interesting to investigate the susceptibility of different fracture modes to the impurity levels, since these could impinge the dislocation motion and influence dislocation storage and twins interaction in this material.

A theoretical program is underway to model the damage evolution observed in materials such as tantalum. The model includes damage induced by shear stress as well as damage caused by volumetric tension. Spallation is included in the model as a special case and strain induced damage is also treated. Void nucleation and growth are taken into account, and give rise to strain rate effects through elastic release wave propagation between damage centers (voids). The underlying physics of the model is the nucleation, growth, and coalescence of voids in a plastically flowing solid. The model is intended for hydrocode based computer simulation. The details of the model are published elsewhere [6].

\section{Conclusions}

We studied damage evolution in tantalum under the spall conditions for impact stresses of 9.5 and $17 \mathrm{GPa}$. The lower shock pressure amplitude (9.5 $\mathrm{GPa})$ formed an incipient spall with the ductile fracture characteristics and cracks in a primary spall plane and cracks extending over several tens of microns in the direction of wave propagation. At high shock pressure the spall was complete and we observed a mixed (ductile and cleavage) fracture mode. Cross sections of the spall surfaces reviled twinning for the high pressure spall case and no twinning in the low pressure case. A theoretical program is underway to model the damage evolution observed in tantalum.

\section{References}

1. G. T. Gray III, "Shock-Loading response of advanced materials," Proc. of AIP Conference on High-Pressure Science and Technology, eds. S. C. Schmidt, J. W. Shaner, G. A. Samara and M. Ross, American Institute of Physics, 1994.

2. A. K. Zurek, P. S. Follansbee, and J. Hack, Met. Trans., 21 (1990) 431-439.

3. J. N. Johnson, R. S. Hixson, D.L. Tonks, and A. K. Zurek, "RateDependent Spallation Properties of Tantalum" in 1995 APS Topical Conference on the Shock Compression of Condensed Matter, 13-18 August, 1995, Seattle, WA.

4. G. T. Gray III and A. D. Rollett, "The high-strain-rate and spallation response of tantalum, Ta-10W, and T-111," in High Strain Rate Behavior of Refractory Metals and Alloys, eds.: R. Asfahani, E. Chen, and A. Crowson, The Minerals, Metals and Materials Society, 1992, pp 303-315.

5. R. W. Armstrong, J. H. Bechtold, and R. T. Begley, "Mechanisms of alloy strengthening in refractory metals," in Refractory Metals and Alloys eds.: R. Asfahani, E. Chen, and A. Crowson, The Minerals, Metals and Materials Society, 1992.

6. D. L. Tonks, A. K. Zurek, and W. R. Thissell, "Ductile Damage Modeling Based on Void Coalescence and Percolation Theories", Proceedings of EXPLOMET'95, The International Conference, El Paso, TX, August 1995. 